\title{
Personalized medicine and Hispanic health: improving health outcomes and reducing health disparities - a National Heart, Lung, and Blood Institute workshop report
}

M. Larissa Avilés-Santa ${ }^{1 *}$, John Heintzman ${ }^{2}$, Nangel M. Lindberg ${ }^{3}$, Rafael Guerrero-Preston ${ }^{4}$, Kenneth Ramos ${ }^{5}$, Ana L. Abraído-Lanza ${ }^{6}$, Jonca Bull 7 , Adolph Falcón ${ }^{8}$, Mary Ann McBurnie $^{3}$, Ernest Moy ${ }^{9}$, George Papanicolaou', lleana L. Piña ${ }^{10}$, Jennifer Popovic ${ }^{11}$, Shakira F. Suglia ${ }^{12}$ and Miguel A. Vázquez ${ }^{13}$

From Personalized Medicine and Hispanic Health: Improving Health Outcomes and Reducing Health Disparities Bethesda, MD, USA. July 06-07, 2017

\begin{abstract}
Persons of Hispanic/Latino descent may represent different ancestries, ethnic and cultural groups and countries of birth. In the U.S., the Hispanic/Latino population is projected to constitute $29 \%$ of the population by 2060 . A personalized approach focusing on individual variability in genetics, environment, lifestyle and socioeconomic determinants of health may advance the understanding of some of the major factors contributing to the health disparities experienced by Hispanics/Latinos and other groups in the U.S., thus leading to new strategies that improve health care outcomes. However, there are major gaps in our current knowledge about how personalized medicine can shape health outcomes among Hispanics/Latinos and address the potential factors that may explain the observed differences within this heterogeneous group, and between this group and other U.S. demographic groups. For that purpose, the National Heart, Lung, and Blood Institute (NHLBI), in collaboration with the National Institute of Diabetes and Digestive and Kidney Diseases (NIDDK), and the Food and Drug Administration (FDA), held a workshop in which experts discussed (1) potential approaches to study medical treatments and health outcomes among Hispanics/Latinos and garner the necessary evidence to fill gaps of efficacy, effectiveness and safety of therapies for heart, lung, blood and sleep (HLBS) disorders and conditions-and their risk factors; (2) research opportunities related to personalized medicine to improve knowledge and develop effective interventions to reduce health disparities among Hispanics/Latinos in the U.S.; and (3) the incorporation of expanded sociocultural and socioeconomic data collection and genetic/genomic/epigenetic information of Hispanic/Latino patients into their clinical assessments, to account for individual variability in ancestry; physiology or disease risk; culture; environment; lifestyle; and socioeconomic determinants of health. The experts also provided recommendations on: sources of Hispanic/Latino health data and strategies to enhance its collection; policy; genetics, genomics and epigenetics research; and integrating Hispanic/ Latino health research within clinical settings.
\end{abstract}

\footnotetext{
* Correspondence: avilessantal@nhlbi.nih.gov

'Division of Cardiovascular Sciences, National Heart, Lung, and Blood

Institute, 6701 Rockledge Drive, Room 10188, Bethesda, MD 20892-7936, USA

Full list of author information is available at the end of the article
} 


\section{Introduction}

Personalized/precision medicine and Hispanic/Latino health Advances in biomedical research and clinical medicine have led to successful treatments for many diseases and significant improvements in health for many Americans. However, many innovative treatments have been developed to treat highly selected patient populations which may not be representative of clinically relevant populations. Despite efforts to advance clinical trial diversity, most trials remain representative of non-Hispanic White (NHWs) populations. Thus, large variations in disease course and response to therapy remain uncharacterized among culturally and racially diverse individuals with similar medical problems. Many of the health disparities documented in the United States are linked to access to care barriers and other socioeconomic determinants of health. But we do not have sufficient information to understand how the interaction between individual physiological/genetic/epigenetic variability, comorbidities, and other health determinants differentially affect members of most culturally and racially diverse communities in the United States, including Hispanic/Latino communities.

Precision medicine uses innovative biological, clinical and population data science tools to customize and personalize disease prevention, detection and treatment, leading to improvements in the effectiveness and quality of patient care [1]. A central goal of precision medicine is to shift disease management and prevention from generalized approaches to personalized care that takes into consideration individual variability in genes, environment and lifestyle [2]. Publicly available genomic and epigenomic tools and databases are fundamental tools for precision medicine efforts. Yet, most of the genomic data available has been collected on NHWs and ancestry related biases are not usually addressed in genetic and precision medicine studies [3, 4].

As of July 2015, the estimated Hispanic/Latino population in the U.S. was 56.6 million or $17.6 \%$ of the U.S. population [5]. It is projected that by 2060, the U.S. Hispanic/Latino population will be 119 million or $28.6 \%$ of the total population [5]. Persons of Hispanic/Latino background may represent different ancestries, ethnic and cultural groups and countries of birth, including the U.S. The term Hispanic often refers to persons who selfidentify or trace their roots to Hispano American countries (former colonies of Spain), and to persons from Spain [6]. The term Latino may be interpreted differently in the U.S. and abroad. Latino refers to persons who self-identify or trace their roots to countries that are former colonies of Spain, Portugal and France (Latin Americans). Hispanic Americans, Hispano Americans or Latin Americans may also trace their roots to other European countries, the Middle East, Africa, and Asia.
In the U.S., the term Latino often refers to Hispanics and Latin Americans, interchangeably. Place of living [7], heritage group [8] or immigrant generation [8] may influence an individual's self-identification as Hispanic, Latino, both or neither. We use the terms Hispanic or Hispanic/Latino interchangeably, and both refer to persons who trace their roots to any Latin American culture.

Significant disparities in health between Hispanics/Latinos and other demographic groups in the U.S. have been amply documented. A personalized approach focusing on individual variability in genetics, environment, lifestyle and socio-economic determinants of health may advance understanding of some of the major factors contributing to the health disparities experienced by Latinos and other groups in the U.S., and lead to new strategies to improve health care outcomes. However, there are major gaps in our current knowledge about how personalized medicine can shape health outcomes among Hispanics/Latinos and address the potential factors that may explain the observed differences within this heterogeneous group and between this group and other U.S. demographic groups.

As part of a series of initiatives focused to make the benefits of precision medicine available to a larger portion of the population and to reduce health disparities among Hispanics/Latinos, the National Heart, Lung, and Blood Institute (NHLBI), the National Institute of Diabetes and Digestive and Kidney Diseases (NIDDK), and the Food and Drug Administration (FDA) planned and sponsored a workshop on July 6-7, 2016, at the main campus of the National Institutes of Health (NIH) in Bethesda, Maryland (USA): Personalized Medicine and Hispanic Health: Contributions to Reducing Health Disparities. The workshop's main objectives were (1) identifying gaps in evidence of efficacy, effectiveness and safety of therapies for heart, lung, blood and sleep (HLBS) disorders and conditions-and their risk factorsaccounting for the racial/ethnic and socioeconomic diversity among Hispanics/Latinos; (2) describing potential approaches to study medical treatments and health outcomes among Hispanics/Latinos and garner the necessary evidence to fill these gaps; and (3) defining research opportunities related to personalized medicine to improve knowledge and develop effective interventions to reduce health disparities among Hispanics/Latinos in the U.S. To fulfill these objectives, the sponsors invited medical and social science professionals, public and health policy experts, geneticists, epidemiologists, clinical investigators, and patient advocates to participate as speakers and panelists. The workshop was open to the public, and videocast live $[9,10]$.

The primary deliverable of the workshop, as detailed in each of the sections of our proceedings, was a set of 
specific and actionable recommendations to address pervasive health disparities among Hispanics/Latinos living in the U.S., and advance research in Hispanic/Latino health with personalized medicine as the ultimate goal. These recommendations represent the consensus opinions expressed by workshop presenters and ratified by contributing authors during the review of the manuscript. Recommendations were summarized for publication with the goal of guiding future efforts among workshop participants and to share specific action items with key stakeholders interested in reducing health disparities and improving health outcomes among Hispanics/Latinos as the evolution of precision/personalized medicine continues to unfold. Implementation of these recommendations are expected to help national initiatives improve efficacy and safety by properly accounting for racial/ethnic and socioeconomic diversity among Hispanics/Latinos, increase accessibility to medical treatments and improved health outcomes and narrow gaps in knowledge and translation of findings for personalizing disease prevention and treatment for Hispanic/Latino patients. The final version of the manuscript was reviewed and approved by National Institutes of Health program officials.

We begin our summary of the workshop with an overview of current research-based knowledge of cardiovascular and pulmonary diseases in Hispanic/Latino populations in the U.S. and participation of Hispanics/ Latinos in clinical research discussed during the workshop. We will then highlight recommendations from the workshop on: sources of Hispanic/Latino health data and strategies to enhance its collection (especially accounting for variability in ancestry, disease risk, culture, environmental factors, lifestyle and socioeconomic determinants of health); policy, genetics, genomics and epigenetics research; and integrating Hispanic/Latino health research within clinical settings. We prefer the term personalized medicine over precision medicine because the person is at the center of individualized preventive and medical care.

\section{Hispanic/Latino Health Research landscape and opportunities}

Cardiovascular and pulmonary diseases in Hispanics/ Latinos in the U.S

Despite being part the fabric of the U.S. population since the country's inception, the inclusion of Hispanic/Latino individuals or populations in research studies has been minimal and regionalized. The first national crosssectional study on Hispanic/Latino health, the Hispanic Health and Nutrition Examination Survey (Hispanic HANES) took place in 1982-1984 [11], and included 16,000 individuals of Mexican, Cuban and Puerto Rican origin. The inclusion of Hispanics in the National Health and Nutrition Examination Survey (NHANES) has primarily represented those of Mexican or Mexican American ancestry [12]. Other observational cross-sectional and longitudinal studies have focused on a specific Hispanic/Latino heritage group [13-18]. There has been a longstanding assumption that Hispanics/Latinos are an ancestrally, culturally and socioeconomically homogeneous group, and the number of studies exploring their differences and similarities (which would enrich the foundational knowledge towards precision/personalized medicine) has been limited [11, 19]. Therefore, the Hispanic Community Health Study/Study of Latinos (HCHS/SOL) has become the most comprehensive study on the health of the contemporary Hispanic/Latino population of the U.S. [20]. In this study, 16,415 individuals who self-identified with Central American, Cuban, Dominican, Mexican, Puerto Rican and South American heritage groups were examined in four U.S. cities, and are followed annually. The national vital statistics report denotes cancer is the leading cause of death among Hispanics/Latinos [21], but cardiovascular disease (CVD) is the second most common cause of death in this population [21]. This study seeks to understand whether there are differences or similarities in cardiovascular and pulmonary health profiles among the different heritage groups at baseline, and if the relationship between the baseline health profile and future health outcomes would differ by heritage group.

The baseline examination, which took place from 2008 to 2011, revealed both similarities and differences in the prevalence of traditional cardiovascular risk factors (obesity, hypertension, diabetes mellitus, dyslipidemia and tobacco use) and other disorders among heritage groups [22]. Diabetes mellitus was more prevalent among Hispanics/Latinos of Dominican, Mexican and Puerto Rican heritage, and less prevalent among those of South American heritage [23]. Differences and similarities in hypertension [24], nutritional intake [25], dietary quality and its relationship to cardiovascular risk factors [26], metabolic syndrome [27], dyslipidemia [28], smoking [29], and sleep disordered breathing [30] were also observed among different heritage groups.

Bronchial asthma was significantly more prevalent among those of Puerto Rican heritage, and lowest among those of Mexican heritage [31]. Chronic obstructive pulmonary disease (COPD) was significantly higher among Hispanics/Latinos of Puerto Rican and Cuban heritage compared to Hispanics/Latinos of other studied heritage groups [31]. In some of these HCHS/SOL analyses the authors described associations between health measurements and socioeconomic indicators, place of birth (U.S.-born versus foreign-born), years living in the U.S., preferred language, and other indicators of acculturation [22, 23, 27-29]. However, those associations have not 
been consistently positive for every $\mathrm{CV}$ risk factor. In addition, genetic studies of the population's principal components [32] and local ancestry [33] revealed substantial genetic differentiation within and among the six heritage groups. It is not completely known whether differences or similarities in genetic ancestry explain the observed phenotypic similarities or differences among Hispanic/Latino heritage groups.

These findings indicate that to reach a deeper understanding of the variations in health-related factors among Hispanics/Latinos in the U.S. and abroad, additional factors ought to be systematically considered. Personal and family medical history, socioeconomic and sociocultural factors throughout a person's life course and across generations, reasons for immigration or migration, history of exposures (e.g. infections, nutrition), education, health beliefs, and practices prior to and after migrating to the U.S. all may potentially shed light on individual or group risk for or protection from specific diseases. In addition, years living in the U.S. and stratification by generation in the U.S. provide context for assessing risk for diseases endemic in the country of origin (e.g., Chagas' disease [34], gastric cancer [35]), versus others more common in the U.S.

In addition to the factors described above, health outcomes for any population may be significantly influenced by access to and quality of healthcare. Since 2003, the annual National Healthcare Quality and Disparities Reports (QDR), generated by the Agency for Healthcare Research and Quality, have shown that Hispanics receive poorer quality health care [36] than NHWs for about $40 \%$ of the measures tracked.

Care for cardiovascular and respiratory diseases mirror these overall patterns as summarized in the 2014 QDR Chartbook on Health Care for Hispanics [37], with Hispanics/Latinos frequently receiving poorer quality care for hypertension, heart attack, heart failure, and asthma. For example, compared with NHWs, non-Mexican Hispanic adults are $11 \%$ less likely to be screened for hypertension and Mexican Americans with hypertension are $35 \%$ less likely to achieve blood pressure control. Hispanic adults have higher hospitalization rates than NHW adults for hypertension, angina, and congestive heart failure. Hispanic men with asthma are $40 \%$ less likely than NHW men to take daily medicine to prevent asthma attacks. Compared with NHW children, Hispanic children have $60 \%$ more emergency department visits for asthma and 70\% more hospitalizations for asthma. In California, Hispanics, especially Spanish speakers, are more likely to be hospitalized in hospitals with low communication scores than NHWs; nonEnglish speakers as a whole are more likely than English speakers to be readmitted following discharge for heart attack or heart failure. While disparities have narrowed for hospital care, disparities remain between Hispanics and NHWs in outpatient care settings and in cardiovascular and respiratory care outcomes.

\section{Participation of Hispanics/Latinos in clinical research}

Clinical trials are an important potential source of information concerning the presence of cardiovascular, pulmonary, blood and sleep diseases/disorders and their risk factors among Hispanics/Latinos. While some of these trials have been rather large [38-40], and adequate representation of Hispanics/Latinos would have been expected, their number has been small. For instance, the percent of Hispanics/Latinos in large clinical trials such as the Antihypertensive and Lipid-Lowering Treatment to Prevent Heart Attack Trial (ALLHAT) [38], Systolic Pressure Intervention Trial (SPRINT) [39], and Action to Control Cardiovascular Risk in Diabetes (ACCORD) [40] ranged between 7 and 12.5. Similarly, the National Emphysema Treatment Trial [41] of lung volume reduction surgery included 1218 patients, of which $99 \%$ were deemed as NHW or African American. These low numbers of Hispanic participants may limit the ability to complete heritage subgroup analyses of treatment effects and outcomes.

In 2012, as part of the FDA Safety and Innovation Act (FDASIA) [42], Congress required the FDA to develop (a) a report on the extent to which demographic data was being collected, analyzed and shared in labeling new safety information over the product life cycle; and (b) an action plan based on the report and stakeholder input. Since 1998, under what is known as the "demographic rule", the FDA has required that sponsors for pharmaceutical and biologic products submit data that identifies sex, race and age [43]. However, concerns were raised by stakeholders concerned about low participation in clinical research by minority groups, and a notable lack of consistent processes to collect data on Hispanic/Latino participation [43, 44]. Consequently, the FDA has issued a revised guidance for reporting of race and ethnicity in clinical trials for the industry and FDA staff [45].

It is anticipated that identification of these issues and the FDA's resulting reporting regulations will lead to strategies that increase participation by Hispanics/Latinos (as well as other minority groups). Barriers to recruitment of and participation by Hispanics/Latinos in clinical trials and personalized medicine research studies must be addressed if we are to develop a personalized medicine approach to Hispanic/Latino health.

\section{Collecting Hispanic/Latino health data}

To apply a personalized medicine approach to the diagnosis, treatment and prevention of HLBS and other chronic diseases in Hispanics/Latinos, research is needed in both efficacy and effectiveness of diagnostic and 
treatment modalities-especially within the context of comorbidities, and factors mentioned above that contribute to the diversity of Hispanics/Latinos. Health care systems, biobanks, registries and claims-based administrative databases hold tremendous potential for a personalized medicine-based approach to the study of Hispanic/Latino health.

- Health Systems: The use of electronic health records (EHRs) has increased significantly during the last two decades. EHRs have the potential to contribute to knowledge regarding patient-level clinical data, including the assessment of continuity of care and comparative effectiveness of treatments; monitoring the impact of new interventions [46]; eliminating unnecessary, inefficient, or ineffective activities; and addressing population-level questions, such as identification of disparities related to prevalence and treatment of health conditions [47-52].

Health systems, particularly those with centralized and searchable EHRs, may have extensive data on Hispanic/ Latino patients, including information on sociodemographic factors, longitudinal service utilization, diagnoses, biomarker data, and insurance coverage (including the uninsured) [53-56]. These types of data have been used in a variety of published analyses on healthcare access, health insurance, and preventive service utilization [57-59].

Challenges with EHR-based health systems data include the heterogeneity in data format, completeness and quality, data collection and management methods, and a lack of interoperability across multiple sites, including ambulatory and hospital environments. Some EHR-based data sources may reflect only ambulatory or in-patient health data. Hispanic/Latino subgroup data are rarely collected uniformly or in significant volume to merit comparisons.

- Biobanks: Store-housed biological samples may provide a large volume of genetic data for prospective evaluation of the genetic and epigenetic contribution to health in Hispanics, and are the focus of recent federal initiatives [60]. Challenges with the use of biobanks for research studies include ensuring a representative sample of individuals from which samples are gathered, linking genetic data to phenotype and environmental data, a limited number of conditions for which genetic information has been shown to be predictive of risk or outcome, ethical issues such as informed consent, and costs in reporting actionable genetic results to research study participants.

- Registries: Patient and disease registries have also been used to describe populations, including
Hispanics, and to track the epidemiology of certain conditions and risk factors [61-63]. Registries often have detailed biological, demographic, and health care information, and cover wide geographic areas and demographic groups [64]. However, registries are limited to certain disease processes, exclude those without specified conditions, and depend on geographic location, initial access to care and subsequent patient involvement to collect data over time. They also lack denominator data; that is, data on the population from which the registry patients were drawn. These features may limit certain at-risk populations from entry into registries [65].

- Claims-based databases: Health insurance claims (or administrative) data allow payers to reimburse health care providers for services rendered. This central billing role also drives the strengths and weaknesses of the use of claims datasets for health research in Hispanic populations. Strengths include the capture of the breadth of an individual's or population's billable, medically attended care over a defined period of observation (health insurance enrollment), regardless of specific provider and facility. Claims are also a cost-effective data source for research-related studies, since they are readily available and do not require any primary data collection.

Limitations of claims-based systems include variation in the quality and completeness of individual data elements on a health care claim form, particularly the lack of reliable race/ethnicity data, and missing information related to out-of-pocket and over-the-counter services. In claims-based systems, information is limited to insured populations, and lacks clinical detail regarding services for which a specific bill is not rendered. Finally, there may be a specific time lag between the provision/ documentation of healthcare events and services, and their appearances in the data warehouse. Claims- and EHR-based systems provide structured data (not freetext clinical notes) captured via well-established coding systems, such as International Classification of Diseases, Ninth Revision, Clinical Modification (ICD-9-CM) (diagnosis and procedure codes used for diagnostic, billing and reporting purposes and mortality coding) [66]; ICD-10 CM (most current version of the ICD) [67]; Current Procedural Terminology (CPT) Codes (determine amount of reimbursement for services provided) $[68,69]$; and National Drug Codes (NDC) Directory (universal product identifier of human drugs in the United States [70]. However, improvements in interoperability are needed. Natural language processing methods might be used to gain additional knowledge from EHR notes fields [71-73]. 


\section{Expanding traditional clinical data collection}

In the context of personalized medicine, the study of human genetic variation is particularly important because genetic variation may account for differences in health outcomes among people from different ethnic or racial groups. This is particularly true for Hispanics/Latinos; it has been demonstrated that despite a less favorable CVD risk factor profile than NHWs and non-Hispanic Blacks, Hispanics exhibit lower cardiovascular mortality, a pattern referred to as the Hispanic Paradox [74, 75]. Based on this and similar paradoxical relationships there has been resurgence of interest in the study of genetic admixture and its impact on the amalgam of races and ethnicities that make up the U.S. population.

In addition to genetic susceptibility, extensive work has documented a relation between social and cultural factors as they impact cardiovascular and pulmonary health. However, research gaps exist on the mechanisms by which these social determinants impact health. Socioeconomic and cultural factors may modulate health and disease via biological mechanisms linked to epigenomic alterations [76, 77], microbiome changes [78, 79], and higher allostatic load [80]. For example, stressors may be experienced across the life course, and research suggests that early childhood exposure to adversity is associated with negative health outcomes in both childhood and adulthood [81, 82]. Epigenomic-mediated stress responses may be one of the molecular mechanisms by which the social environment becomes biology.

To maximize efficacy, a personalized medicine approach might take into account sociocultural and structural contexts that promote or present barriers to health. For example, referrals for medical treatments and regimens to improve cardiovascular health (e.g., medications for hypertension, plus a physical activity regimen) must consider the built environment (lack of safe walking trails or exercise facilities) that hinder the ability to follow the prescribed regime. Such lifestyle approaches may hold the greatest promise in tailoring medicine, genetics, and individual biology to the environment in which individuals live [83].

\section{Discussion- recommendations}

The final workshop discussion was dedicated to potential strategies for effectively implementing research within clinical settings, and for engaging stakeholders in this process. The following are the key recommendations resulting from this discussion.

\section{Improve data collection strategies through existing networks of health care systems and clinics}

While the implementation of current medical guidelines for prevention and care should continue, relevant data to help us understand the effectiveness and safety profile of therapies for HBLS diseases and their interaction with other factors across Hispanic/Latino heritage groups needs to be simultaneously assessed. These data would be best collected through a dedicated network of health care systems and clinics, in concert with other databases described above. Such a dedicated network could be based on existing platforms and designed to leverage the expertise of regional health information organizations. And considering advantages and disadvantages of these databases previously described (e.g., health systems, biobanks, registries, claims-based databases), potential opportunities to enhance and expand these should be explored.

- In addition to clinical and demographic data (e.g., existing medical conditions, hospitalizations, medications), datasets should be enriched with expanded information on Hispanic/Latino identifiers, place of birth, travel and migration history, and expanded socioeconomic assessments; effectiveness and interaction of pharmacological and non-pharmacological treatments; genetic/genomic and molecular data; drug/surgery adverse events; comorbidities; use of over-the-counter drugs and dietary supplements, and traditional herbal and nonherbal remedies; and changes in nutrition and physical activity.

- Standardized data dictionaries focused on Hispanic/ Latino health are essential and should be created.

- Appropriate expertise must be integrated into data networks to link datasets and systems efficiently and effectively. This kind of linking (for instance, claims and EHR databases) is expensive and time consuming, but can be very valuable for understanding personalized medicine. The interoperability of EHR systems could be enhanced by policies, such as the required collection of standardized key data elements (e.g., more granular ethnicity, country of birth, parents' country of birth) and data management processes (e.g., patient matching procedures) to improve the completeness and quality of EHR data. Examples of such policies include Meaningful Use Core Measure on Smoking Status [84], HRSA's collection of sexual orientation/gender identity data [85], and ONC's Patient Matching Initiative [86, 87]. Using and expanding existing models of already integrated systems and leveraging the expertise of established networks could save time. As in any health network, a methodology to search for and handle missing data needs to be developed and validated.

\section{Require inclusion of race/ethnicity data in all health- related datasets}

A minimal set of identifiers of Hispanic/Latino heritage/ identity should be incorporated into data collection 
platforms. Race/ethnicity self-identification is preferable over identification assigned by administrative staff, researchers or health care providers, since it is likely to be more accurate. Self-identification should be expanded beyond the blanket terms "Hispanic" or "Latino" to include more granular information on nationality, cultural ancestry and/or heritage [88]. This minimal set of identifiers should include standard definitions, which could be incorporated into the EHR.

\section{Strengthen guidance to researchers by rewarding inclusive study designs}

Besides the current policy on inclusion of women and minorities as subjects in biomedical research [89], the processes for reviewing and awarding of grants could place greater value on (1) studies demonstrating power of the subject sample by sex, race, and ethnicity, when appropriate; (2) a plan to report findings by sex, race, and ethnicity, and eventually publish the findings; (3) innovative models of inclusion and academic-community partnerships, like community-based participatory research, when appropriate; and (4) applications proposing sites for multicenter grants that represent the diversity of the U.S. population, including the diverse Hispanic/ Latino heritage groups. Furthermore, it is critical that review boards reflect inclusive excellence. These steps will help improve the current status quo whereby Hispanics/ Latinos represent $17.4 \%$ of the U.S. general population, but $7.2 \%$ of biomedical doctoral degrees, and only $3.4 \%$ of NIH-funded principalinvestigators [90].

\section{Integrate genetic and epigenomic data into the electronic medical record}

Advancing our current understanding of Hispanic/Latino health will require the use of genetic and epigenomic data to more precisely define the taxonomy of disease processes and to optimize therapies, while minimizing adverse reactions. Such interventions have proven extremely valuable in the management of several diseases including cardiomyopathies [91, 92] and diseases of the lung [93]. To ensure that precision medicine pipelines include Hispanic/Latino populations, molecular research efforts must be set in motion to identify: 1) genetic and epigenomic biomarkers associated to causal or risk factors; 2) underlying genetic and epigenetic alterations that lead to manifest disease, and 3) genetic and epigenomic markers relevant to prognosis and prevention.

To achieve these goals, it is imperative to increase genomic/epigenomic research Hispanic/Latino populations. For instance, Popejoy and Fullerton reported that in 20 years the representation of Hispanics/Latinos in genome-wide association studies rose from $0.06 \%$ to $0.54 \%$ [94]. The participation of the HCHS/SOL in the Trans-Omics for Precision Medicine (TOPMed) Program is helping to change these numbers, since TOPMed aims at collecting and assembling -omics data across diverse populations including those traditionally underrepresented in research [95]. Furthermore, analyses should focus on novel findings as opposed to confirmation of variants or genes from non-Hispanic populations and be devoid of biases that arise when cross-population analyses are prioritized towards non-Hispanic populations. Resources need to be developed that explore and make available both population specific variants and methods that incorporate admixed populations, as well as ancestral variation. Importantly, however, genetic and epigenomic data that define the biological contributions of admixture should be combined with the study of the epigenome at different life stages. Personalized medicine will be driven by personalized maps of epigenomic alterations of disease risk and causality associated to health behavior, neighborhood effects, allostatic load, the microbiome and other health determinants in Hispanic/Latino populations.

\section{Prioritize research on Hispanic/Latino populations not currently represented in national studies or the All of Us initiative}

Originating from over 20 countries, Hispanic/Latino heritage groups in the U.S. have diverse sociodemographic and health profiles [96,97]. Although there is growing recognition of differing health patterns and profiles [96, 97], data on health or health behaviors are still scarce for specific heritage groups and for geographic locations in which Hispanic/Latino communities are emerging or have been recently established.

Many Hispanic/Latino health research studies have been based on samples in California and the Southwest, followed by some locations in the Midwest and the Northeast. However, very few draw from other geographic locations with a significant percent of Hispanics/ Latinos (e.g. the Washington DC area) or with emerging Hispanic/Latino communities [98]. Salvadorans and Dominicans constitute the fourth and fifth largest Hispanic/Latino heritage groups in the U.S, respectively. However, they are seldom represented in research studies or national surveys. Puerto Rico, a U.S. territory, is included in the Behavioral Risk Factor Surveillance System (BRFSS) [99], but not in National Health and Nutrition Examination Survey (NHANES) [100], the MultiEthnic Study of Atherosclerosis (MESA) [101] or the HCHS/SOL [20].

To assure progress in promoting the best health outcomes for all, research programs must include meaningful participation from all Hispanic/Latino heritage groups represented in the U.S. population. 


\section{Integrate Hispanic/Latino health-related research within clinical settings}

More research in Hispanic/Latino health should be performed in community clinical settings rather than academic settings for the following reasons.

- Research in community clinical settings offers the possibility of collecting new data and accessing existing relevant data, addressing patient-centered concerns, and improving patient care outcomes. Clinical settings provide the ability to identify potential research participants with specific exposures or diagnoses through EHR, ascertain health outcomes, validate diagnosis codes, estimate disease or risk factor incidence rates, and identify persons with new disease onset [51, 102]. In addition, having access to health care providers in clinical settings may illuminate barriers and facilitators to recommended care guidelines. Quasi-experimental designs and clusterrandomized studies provide pragmatic research approaches that mitigate the research burden on clinic workflow [103].

- Results of research based in clinical settings can be more generalizable. The patients served in community clinical settings or health systems experience a broad range of healthcare environments, social determinants of health, and complex co-morbidities [51]. The results of research studies in these settings would be more representative of those communities than results of research carried out in academic settings, which tend to be highly selective with respect to patients, providers and healthcare environments [49-52].

Research integrated into clinical settings also presents unique and difficult challenges. A recent survey of PCORnet awardees and stakeholders identified those challenges [104] which included: excessive burden on clinic staff and clinic resources, researchers' lack of knowledge about some aspects of the health care enterprise (i.e., customer service, resource utilization), clashing of differing professional cultures, and low patient engagement.

Inadequate access to health care is a barrier to the benefits of new discovery and precision medicine; about $20 \%$ of Hispanics remain uninsured compared to $10 \%$ of NHWs [105]. The inclusion of safety-net-based healthcare settings/data resources will capture at least some of these patients and should be mandatory for research involving Hispanic/Latino populations.

Finally, approaches to enhance participation of Hispanics/Latinos in research should consider patients' educational attainment, employment-related (e.g., work shift, lost wages), transportation, preferred mode of communication (in-person versus phone call versus mail), preferred language, past experience with medical or government systems, cultural beliefs and personal expectations about health maintenance and disease treatment and prevention, among others.

\section{Engage stakeholders at multiple levels of the research enterprise}

The collaborative efforts of multiple system stakeholders working together toward a common goal could significantly reduce barriers to successful conduct of biomedical research involving Hispanic populations [106]. Team science and inclusion of non-scientific experts in the research design should be promoted. Teams should include clinicians, experts in clinical trials, social/ psychosocial experts, genetics/genomics experts, recruitment experts, case managers, administrative personnel, information technology analysts, interpreters, patient advocates, patients, community members, educators, and students.

Optimal stakeholder engagement is fostered by a bidirectional approach (both top-down and bottom-up) in communication in all stages of research, from planning to implementation. Participation of administrators and front-line clinic staff in the planning stages of a research project is likely to result in a more seamless transition between clinical and research tasks that staff members are often involved in. This transition will also increase staff members' sense of ownership of the research project, which is in turn may increase the likelihood of project success.

Clinicians of Hispanic/Latino origin who are associated with academic medical centers or community clinical centers may play a key role in educating Hispanic/ Latino patients about clinical trials and how they could contribute towards the understanding of their own health and their families' health. Also, investigators in academic institutions may invite physicians in the community to become points of referral of Hispanic/Latino patients, and, in turn, become an integral part of the research team. Finally, the creation of a national Hispanic/ Latino Patient Advisory Panel could identify, engage in and advocate for resources and policies that would support enhanced research among Hispanic populations.

\section{Increase and enhance Hispanic/Latino scientific workforce}

Increasing the participation of Hispanic/Latino individuals in all aspects of the health-care workforce, from healthcare to scientific research, is essential to provide culturally competent care to the growing U.S. Hispanic/ Latino population [107]. It is imperative to increase Hispanic/Latino access to educational opportunities, and efforts to identify, recruit, and retain talented Hispanic/ Latino students in the STEM and biomedical disciplines pipeline starting at the elementary school level, and to 
prospectively plan recruitment of talented Hispanic/Latino scientists and promotion of Hispanic/Latino faculty to positions of leadership in academia and funding agencies. Hispanic/Latino researchers or health care providers may enhance awareness of ethnicity-based differences in disease prevalence or symptomatology, which could reduce health disparities and improve treatment outcomes in this population [108].

\section{Conclusions}

We know that diversity in our scientific enterprise is vital to improving the health care of our nation. Recent research has confirmed what has long been suspected: there are major differences in the safety and effectiveness of many treatments, with a key variable being the gender, race and ethnicity of the individual. The only way we can make progress in building a strong foundation for personalized medicine is to meaningfully include all Hispanic/Latino heritage groups represented in the U.S. population in health-related research projects. We hope that the recommendations of the NIH Workshop on Precision Medicine and Hispanic Health will move the nation forward in securing the best health outcomes for all.

\section{Acknowledgments}

The authors would like to thank Laura Jacobson (New York City Department of Health and Mental Hygiene), Jean Lawrence, ScD (Kaiser Permanente Southern California), Barbara Christensen, RN (American College of Cardiology), Kevin Abbott, PhD (NIDDK), Lindsey Enewold, PhD (NCl), Eimear Kenny, PhD (Mount Sinai Icahn School of Medicine), Ed Ramos, PhD (National Institute on Biomedical Imaging and Bioengineering) for their valuable contributions to presentations and discussions.

The authors would also like to thank Sonia Arteaga, PhD (NHLBI), Silvia Dossmann (NHLBI), Lisa LaVange, PhD (FDA), Barbara Linder, MD (NIDDK), Martin Mendoza, MD, PhD (FDA), George Mensah, MD (NHLBI), Mollie Minear, $\mathrm{PhD}(\mathrm{NHLBI})$, Jeannie Olson, MD, MPH (NHLBI), Eliseo Pérez-Stable, MD (Director of the National Institute on Minority Health and Health Disparities), LaShawndra Price, PhD (NHLBI), Mona Puggal, MPH (NHLBI), Catalina Ramos, RN (NHLBI), Yanira Ruiz-Perdomo, FNP-BC (National Institute of Arthritis and Musculoskeletal and Skin Diseases), Kathryn Valeda (NHLBI), Barbara Wells, $\mathrm{PhD}(\mathrm{NHLBI})$ for their input, assistance or participation in different stages of the organization of this workshop, and Jeannie Olson (NHLBI) and Jill Pope (Kaiser Permanente Center for Health Research) for their assistance with the editing of this manuscript.

And our deepest appreciation to Mr. and Mrs. Cabrera for sharing their personal story as clinical trial participants.

\section{Funding}

This workshop was co-funded by the NHLBI, NIDDK and the FDA. Funds for publication of this manuscript were provided by NHLBI.

\section{Authors' contributions}

MLAS, JH, NML, RGP, KR, ALAL, JB, AF, MAM, EM, GP, ILP, JP, SFS, and MAV were speakers at workshop. Each one of them contributed with the discussion following the workshop, and wrote different sections of the manuscript, including the recommendations. MLAS organized and designed the manuscript. All authors read and approved the final manuscript.

\section{Competing interests}

The authors have no conflicts of interest to disclose.

The views expressed in this manuscript are those of the authors and do not necessarily represent the views of the National Heart, Lung, and Blood Institute; the National Institutes of Health; or the U.S. Department of Health and Human Services.

\section{Publisher's Note}

Springer Nature remains neutral with regard to jurisdictional claims in published maps and institutional affiliations.

\section{Author details}

'Division of Cardiovascular Sciences, National Heart, Lung, and Blood Institute, 6701 Rockledge Drive, Room 10188, Bethesda, MD 20892-7936, USA. ${ }^{2}$ Department of Family Medicine, Oregon Health and Science University, 318 SW Sam Jackson Park Rd, Portland, OR 97239, USA. ${ }^{3}$ Kaiser Permanente Northwest Center for Health Research, 3800 N. Interstate Ave, Portland, OR 97227, USA. ${ }^{4}$ Johns Hopkins University School of Medicine, 1550 Orleans Street, CRB2 Room 5M, Baltimore, MD 21231, USA. ${ }^{5}$ University of Arizona Health Sciences, 1295 North Martin Avenue, PO Box 210202, Tucson, AZ 86721 , USA. ${ }^{6}$ Columbia University, Mailman School of Public Health, 722 West 168th Street, New York, NY 10032, USA. ${ }^{7}$ Office of Minority Health, U.S. Food and Drug Administration, 10903 New Hampshire Avenue, Silver Spring, MD 20993, USA. ${ }^{8}$ National Alliance for Hispanic Health, 1600 P St NW,

Washington, DC 20009, USA. ${ }^{9}$ National Center for Health Statistics, 3311 Toledo Road, Hyattsville, MD 20782, USA. ${ }^{10}$ Albert Einstein College of Medicine, Montefiore Heart and Vascular Center, 111 East 210th Street, Bronx, NY 10467-2401, USA. ${ }^{11}$ Program for Health Data and Standardized Methods, Center for Health Data Analytics | eHealth, Quality \& Analytics Division, RTI International | 307 Waverley Oaks Road, Suite 101, Waltham, MA 02452, USA. ${ }^{12}$ Rollins School of Public Health, Emory University, 1518 Clifton Rd Rm 4005, Atlanta, GA 30322, USA. ${ }^{13}$ Department of Internal Medicine, University of Texas Southwestern Medical Center, 5323 Harry Hines Boulevard, Dallas, TX 75390-8856, USA.

Published: 3 October 2017

\section{References}

1. Collins FS, Varmus H. A new initiative in precision medicine. N Eng J Med. 2015;372(9):793-5.

2. Fradkin JE, Hanlon MC, Rodgers GP. NIH precision medicine initiative: implications for diabetes research. Diabetes Care. 2016;39:1080-4.

3. Kessler MD, Yerges-Armstrong L, Taub MA, Shetty AC, Maloney K, Jeng L, Ruczinski I, Levin AM, Williams LK, Beaty TH, Mathias RA, Barnes KC. Consortium on Asthma among African-ancestry Populations in the Americas (CAAPA)., O'Connor TD. Challenges and disparities in the application of personalized genomic medicine to populations with African ancestry. Nat Commun. 2016;7:12521.

4. Ortega VE, Meyers DA. Pharmacogenetics: implications of race and ethnicity on defining genetic profiles for personalized medicine. J Allergy Clin Immunol. 2014;133:16-26

5. United States Census Bureau: Profile America Facts for Features, CB16-FF.16 Hispanic Heritage Month 2016. https://census.gov/newsroom/facts-forfeatures/2016/cb16-ff16.html. Accessed 31 Aug 2017.

6. Colby SL, Ortman JM, Projections of the Size and Composition of the U.S. Population: 2014 to 2060, Current Population Reports, P25-1143, U.S. Census Bureau, Washington, DC, 2014.

7. Lopez MH, Hispanic or Latino? Many don't care, except in Texas. Pew Research Center, October 28, 2013. http://www.pewresearch.org/fact-tank/ 2013/10/28/in-texas-its-hispanic-por-favor/. Accessed 31 Aug 2017.

8. Lopez MH, Hispanic Identity. Pew Research Center Hispanic Trends, October 22, 2013. http://www.pewhispanic.org/2013/10/22/3-hispanic-identity/. Accessed 31 Aug 2017.

9. Personalized Medicine and Hispanic Health Workshop - July 2016 (Day 1). https://videocast.nih.gov/summary.asp? Live=19390\&bhcp=1. Accessed 31 Aug 2017.

10. Personalized Medicine and Hispanic Health Workshop - July 2016 (Day 2). https://videocast.nih.gov/summary.asp?Live $=19394 \& b h c p=1$. Accessed 31 Aug 2017.

11. Delgado JL, Johnson CL, Treviño FM. Hispanic Health Nutrition and Examination Survey: Methodological Considerations. Am J Public Health. 1990;80(Suppl):6-10.

12. Menke A, Casagrande S, Geiss L, Cowie CC. Prevalence of and trends in diabetes among adults in the US, 1988-2012. JAMA. 2016;314:1021-9.

13. Stern MP, Rosenthal M, Haffner SM, Hazuda HP, Franco LJ. Sex difference in the effect of sociocultural status on diabetes and cardiovascular risk factors in Mexican Americans: The San Antonio Heart Study. Am J Epidemiol. 1984;120:834-51. 
14. Hamman RF, Marshall JA, Baxter J, Kahn LB, Mayer EJ, Orleans M, Murphy JR, Lezotte DC. Methods and prevalence of non-insulin dependent diabetes mellitus in a biethnic Colorado population: The San Luis Valley Diabetes Study. Am J Epidemiol. 1989;129:295-311.

15. Goff DC, Ramsey DJ, Labarthe DR, Nichaman MZ. Greater case fatality after myocardial infarction among Mexican Americans and women than among non-Hispanic whites and men: The Corpus Christi Heart Project. Am J Epidemiol. 1994;139:474-83.

16. Ostir GV, Markides KS, Freeman DH, Goodwin JS. Obesity and health conditions in elderly Mexican Americans: the Hispanic EPESE. Established Population for Epidemiologic Studies of the Elderly. Ethn Dis 2000; 10: 31 38, PMID: 10764128.

17. Tucker KL, Bermudez OI, Castaneda C. Type 2 diabetes is prevalent and poorly controlled among Hispanic elders of Caribbean origin. Am J Public Health. 2000;90:1288-93.

18. Vidal CM, García-Palmieri MR, Costas R, Sorlie PD, Havlik RJ. Abnormal blood glucose and coronary heart disease: the Puerto Rico Heart Health Program. Diab Care. 1983;6:556-61.

19. Alegria M, Takeuchi D, Canino G, Duan N, Shrout P, Meng X-L, Vega W, Zane N, Vila D, Woo M, Vera M, Guarnaccia P, Aguilar-Gaxiola S, Sue S, Escobar J, Lin KM, Gong F. Considering place, context and culture: the National Latino and Asian American Study. Int J Methods Psych Res. 2004;13:208-20.

20. Sorlie PD, Avilés-Santa ML, Wassertheil-Smoller S, Kaplan RC, Daviglus ML, Giachello A, Schneiderman N, Raij L, Talavera G, Allison M, LaVange LM, Chambless LE, Heiss G. Design and implementation of the Hispanic Community Health Study/ Study of Latinos. Ann Epidemiol. 2010;20:629-41.

21. Heron M. Deaths: Leading causes for 2014. National vital statistics reports; Vol 65 no 5. Hyattsville, MD: National Center for Health Statistics. 2016.

22. Daviglus ML, Talavera GA, Avilés-Santa ML, Allison M, Cai J, Criqui MH, Gellman M, Giachello AL, Gouskova N, Kaplan RC, LaVange L, Penedo F, Perreira K, Pirzada A, Schneiderman N, Wassertheil-Smoller S, Sorlie PD, Stamler J. Prevalence of major cardiovascular risk factors and cardiovascular diseases among Hispanic/Latino individuals of diverse backgrounds in the United States. JAMA. 2012;308:1775-84.

23. Schneiderman N, Llabre M, Cowie CC, Barnhart J, Carnethon M, Gallo LC, Giachello AL, Heiss G, Kaplan RC, LM LV, Teng Y, Villa-Caballero L, AvilésSanta ML. Prevalence of diabetes among Hispanics/Latinos from diverse backgrounds: the Hispanic Community Health Study/Study of Latinos (HCHS/SOL). Diabetes Care. 2014;37:2233-9.

24. Sorlie PD, Allison MA, Avilés-Santa ML, Cai J, Daviglus ML, Howard AG, Kaplan R, Lavange LM, Raij L, Schneiderman N, Wassertheil-Smoller S, Talavera GA. Prevalence of hypertension, awareness, treatment, and control in the Hispanic Community Health Study/Study of Latinos. Am J Hypertension. 2014;27:793-800.

25. Siega-Riz AM, Sotres-Alvarez D, Ayala GX, Ginsberg M, Himes JH, Liu K, Loria CM, Mossavar-Rahmani Y, Rock CL, Rodriguez B, Gellman MD, Van Horn L. Food-group and nutrient-density intakes by Hispanic and Latino backgrounds in the Hispanic Community Health Study/Study of Latinos. Am J Clin Nutr. 2014 Jun;99:1487-98. https://doi.org/10.3945/ajcn.113.082685.

26. Mattei J, Sotres-Alvarez D, Daviglus ML, Gallo LC, Gellman M, Hu FB, Tucker KL, Willett WC, Siega-Riz AM, Van Horn L, Kaplan RC. Diet Quality and Its Association with Cardiometabolic Risk Factors Vary by Hispanic and Latino Ethnic Background in the Hispanic Community Health Study/Study of Latinos. J Nutr. 2016;146:2035-44.

27. Rodriguez CJ, Daviglus ML, Swett K, González HM, Gallo LC, WassertheilSmoller S, Giachello AL, Teng Y, Schneiderman N, Talavera GA, Kaplan RC. Dyslipidemia patterns among Hispanics/Latinos of diverse background in the United States. Am J Med. 2014;127:1186-1194, e1. https://doi.org/10. 1016/j.amjmed.2014.07.026.

28. Heiss G, Snyder ML, Teng Y, Schneiderman N, Llabre MM, Cowie C, Carnethon M, Kaplan R, Giachello A, Gallo L, Loehr L, Avilés-Santa L. Prevalence of metabolic syndrome among Hispanics/Latinos of diverse background: the Hispanic Community Health Study/Study of Latinos. Diab Care. 2014;37:2391-9. https://doi.org/10.2337/dc13-2505.

29. Kaplan RC, Bangdiwala SI, Barnhart JM, Castañeda SF, Gellman MD, Lee DJ, Pérez-Stable EJ, Talavera GA, Youngblood ME, Giachello AL. Smoking among U.S. Hispanic/Latino adults: the Hispanic community health study/ study of Latinos. Am J Prev Med. 2014;46:496-506. https://doi.org/10.1016/j. amepre.2014.01.014.

30. Redline S, Sotres-Alvarez D, Loredo J, Hall M, Patel SR, Ramos A, Shah N, Ries A, Arens R, Barnhart J, Youngblood M, Zee P, Daviglus ML. Sleep-disordered breathing in Hispanic/Latino individuals of diverse backgrounds. The Hispanic Community Health Study/Study of Latinos. Am J Respir Crit Care Med. 2014;189:335-44. https://doi.org/10.1164/rccm.201309-17350C.

31. Barr RG, Avilés-Santa L, Davis SM, Aldrich TK, Gonzalez F, Henderson AG, Kaplan RC, LaVange L, Liu K, Loredo JS, Mendes ES, Ni A, Ries A, Salathe M, Smith LJ. Pulmonary disease and age at immigration among Hispanics. Am J Respiratory Critical Care Med. 2016;193:386-95.

32. Conomos MP, Laurie CA, Stilp AM, Gogarten SM, McHugh CP, Nelson SC, Sofer T, Fernandez-Rhodes L, Justice AE, Graff M, et al. Genetic diversity and association studies in US Hispanic/Latino populations: applications in the Hispanic Community Health Study/Study of Latinos. Am J Human Genetics. 2016;98:165-84.

33. Browning SR, Grinde K, Plantinga A, Gogarten SM, Stilp A, Kaplan RC, AvilesSanta ML, Browning BL, Laure CC. Local ancestry inference in a large USbased Hispanic/Latino Study: the Hispanic Community Health Study/Study of Latinos. G3. 2016;6:1525-34.

34. Montgomery SP, Parise ME, Dotson EM, Bialek SR. What Do We Know about Chagas Disease in the United States. Am J Trop Med Hyg. 2016 Dec 7;95:1225-7.

35. Bautista MC, Jiang SF, Armstrong AM, Kakar S, Postlethwaite D, Li D. Significant Racial Disparities Exist in Noncardia Gastric Cancer Outcomes Among Kaiser Permanente's Patient Population. Dig Dis Sci. 2015;60:984-95.

36. Quality and Disparities in Quality of Health Care. National Healthcare Quality and Disparities Report and $5^{\text {th }}$ Anniversary Update on the National Quality Strategy. Rockville, MD: Agency for Healthcare Research and Quality; 2015. http://www.ahrq.gov/research/findings/nhqrdr/nhqdr15/quality.html. Accessed 31 Aug 2017.

37. 2014 National Healthcare Quality and Disparities Report chartbook on health care for Hispanics. Rockville, MD: Agency for Healthcare Research and Quality; September 2015. AHRQ Pub. No. 15-0007-11-EF. https://www.ahrq. gov/research/findings/nhqrdr/2014chartbooks/hispanichealth/index.html. Accessed 31 Aug 2017.

38. The ALLHAT Officers and Coordinators for the ALLHAT Collaborative Research Group. Major outcomes in high-risk hypertensive patients randomized to angiotensin-converting enzyme inhibitor or calcium channel blocker vs diuretic: The Antihypertensive and Lipid-Lowering Treatment to Prevent Heart Attack Trial (ALLHAT). JAMA. 2002;288(23):2981-97.

39. The SPRINT Research Group. A randomized trial of intensive versus standard blood pressure control. N Eng J Med. 2015;373:2103-16.

40. The ACCORD Study Group. Effects of Intensive Blood-Pressure Control in Type 2 Diabetes Mellitus. N Engl J Med. 2010;362:1575-85.

41. National Emphysema Treatment Trial Research Group. A Randomized Trial Comparing Lung-Volume-Reduction Surgery with Medical Therapy for Severe Emphysema. N Engl J Med. 2003;348:2059-73.

42. U.S. Food and Drug Administration, Regulatory Information. Food and Drug Administration Safety and Innovation Act (FDASIA). https://www.fda.gov/ RegulatoryInformation/LawsEnforcedbyFDA/SignificantAmendmentstotheFDCAct/ FDASIAVucm20027187.htm. Accessed 1 Sept 2017.

43. FDA Report: Collection, Analysis, and Availability of Demographic Subgroup Data for FDA-Approved Medical Products, issued August 2013, required under FDASIA Section 907. http://www.fda.gov/downloads/ RegulatoryInformation/Legislation/FederalFoodDrugandCosmeticActFDCAct/ SignificantAmendmentstotheFDCAct/FDASIA/UCM365544.pdf. Accessed 31 Aug 2017.

44. FDA Report: FDA Action Plan to enhance the collection and availability of demographic and subgroup data, August 2014 https://www.fda.gov/ downloads/RegulatoryInformation/Legislation/FederalFoodDrugand CosmeticActFDCAct/SignificantAmendmentstotheFDCAct/FDASIA/ UCM410474.pdf. Accessed 31 Aug 2017.

45. Collection of Race and Ethnicity Data in Clinical trials: Guidance for Industry and Food and Drug Administration Staff, October 26, 2016. http://www.fda. gov/downloads/Regulatorylnformation/Guidances/UCM126396.pdf. Accessed 31 Aug 2017.

46. Platt R, Wilson M, Chan A, Benner JS, Marchibroda J, McClellan M. The new Sentinel Network - improving the evidence of medical-product safety. N Engl J Med. 2009;361:645-7.

47. Fahey KR. The Pioneering Role of the Vaccine Safety Datalink Project (VSD) to Advance Collaborative Research and Distributed Data Networks. EGEMS (Wash DC). 2015;3:1195. 10.13063/2327-9214.1195.

48. Laws R, Gillespie S, Puro J, Van Rompaey S, Quach T, Carroll J, Weir RC, Crawford P, Grasso C, Kaleba E, McBurnie MA. The Community Health Applied Research Network (CHARN) data warehouse: A resource for patient- 
centered outcomes research and quality improvement in underserved, safety net populations. EGEMS. 2014;2:1097.

49. Nichols GA, McBurnie MA, Paul L, Potter JE, McCann S, Mayer K, Melgar G, D'Amato S, DeVoe JE. The high prevalence of diabetes among a large cohort of patients drawn from safety net clinics. Prev Chronic Dis. 2016;13:E78.

50. Mayer KH, Crawford P, Dant L, Gillespie S, Singal R, Vandermeer M, Muench J, Long T, Quach T, Chaudhry A, Crane HM, Lembo D, Mills R, McBurnie MA. HIV and Hepatitis C virus screening practices in a geographically diverse sample of American community health centers. AIDS Patient Care STDS. 2016;30:237-46.

51. Li V, McBurnie MA, Simon M, Crawford P, Leo M, Rachman F, Cottrell E, Dant L, Oneha M, Chang WR. Impact of social determinants of health on patients with complex diabetes who are served by national safety-net health centers. J Am Board Fam Med. 2016:29:356-70.

52. Rieckmann T, Muench J, McBurnie MA, Leo MC, Crawford P, Ford D, Stubbs J, O'Cleirigh C, Mayer KH, Fiscella K, Wright N, Doe-Simkins M, Cuddeback M, Salisbury-Afshar E, Nelson C. Medication-assisted treatment for substance use disorders within a national community health center research network. Subst Abus. 2016;37:625-34.

53. Bazemore AW, Cottrell EK, Gold R, Hughes LS, Phillips RL, Angier H, Burdick TE, Carrozza MA, DeVoe JE. "Community vital signs": incorporating geocoded social determinants into electronic records to promote patient and population health. J Am Med Inform Assoc. 2016;23:407-12. https://doi. org/10.1093/jamia/ocv088.

54. DeVoe JE, Gold R, Cottrell E, Bauer V, Brickman A, Puro J, Nelson C, Mayer $\mathrm{KH}$, Sears A, Burdick T, Merrell J, Matthews P, Fields S. The ADVANCE network: accelerating data value across a national community health center network. J Am Med Inform Assoc. 2014;21:591-5. https://doi.org/10.1136/ amiajnl-2014-002744

55. DeVoe JE, Sears A. The OCHIN community information network: bringing together community health centers, information technology, and data to support a patient-centered medical village. J Am Board Fam Med. 2013;26: 271-8. https://doi.org/10.3122/jabfm.2013.03.120234.

56. Heintzman J, Bailey SR, DeVoe J, Cowburn S, Kapka T, Duong TV, Marino M. In Low-Income Latino Patients, Post-Affordable Care Act Insurance Disparities May Be Reduced Even More than Broader National Estimates: Evidence from Oregon. J Racial Ethn Health Disparities. 2017:4:329-36. https://doi.org/10.1007/s40615-016-0232-1

57. Heintzman J, Marino M, Hoopes M, Bailey S, Gold R, Crawford C, Cowburn S, O'Malley J, Nelson C, DeVoe JE. Using electronic health record data to evaluate preventive service utilization among uninsured safety net patients. Prev Med. 2014;67:306-10. https://doi.org/10.1016/j. ypmed.2014.08.006.

58. Heintzman J, Marino M, Hoopes M, Bailey SR, Gold R, O'Malley J, Angier H, Nelson C, Cottrell E, DeVoe JE. Supporting health insurance expansion: do electronic health records have valid insurance verification and enrollment data? J Am Med Inform Assoc. 2015;22:909-13. https://doi.org/10.1093/ jamia/ocv033.

59. Heintzman JB, Bailey SR, Cowburn S, Dexter E, Carroll J, Marino M. Pneumococcal Vaccination in Low-Income Latinos: An Unexpected Trend in Oregon Community Health Centers. J Health Care Poor Underserved. 2016;27:1733-44

60. All of Us Research Program. National Institutes of Health. https://www.nih. gov/precision-medicine-initiative-cohort-program. Accessed 31 Aug 2017.

61. Akinyemiju T, Moore JX, Ojesina Al, Waterbor JW, Altekruse SF. Racial disparities in individual breast cancer outcomes by hormone-receptor subtype, area-level socio-economic status and healthcare resources. Breast Cancer Res Treat. 2016;157(3):575-86. https://doi.org/10.1007/ s10549-016-3840-X.

62. Ooi SL, Martinez ME, Li Cl. Disparities in breast cancer characteristics and outcomes by race/ethnicity. Breast Cancer Res Treat. 2011;127(3):729-38. https://doi.org/10.1007/s10549-010-1191-6.

63. Rahman R, Schmaltz C, Jackson CS, Simoes EJ, Jackson-Thompson J, Ibdah JA. Increased risk for colorectal cancer under age 50 in racial and ethnic minorities living in the United States. Cancer Med. 2015:4:1863-70. https:// doi.org/10.1002/cam4.560.

64. Surveillance, Epidemiology, and End Results (SEER) Program). SEER*Stat Database: Incidence - SEER 9 Regs Research Data, Nov 2015 Sub (19732013) - Linked To County Attributes - Total U.S., 1969-2014 Counties. 2015. Retrieved from http://www.seer.cancer.gov/. Accessed 31 Aug 2017.
65. Kuo TM, Mobley LR. How generalizable are the SEER registries to the cancer populations of the USA. Cancer Causes Control. 2016;27:1117-26. https:// doi.org/10.1007/s10552-016-0790-x.

66. Cartwright DJ. ICD-9-CM to ICD-10-CM Codes: What? Why? How. Adv Wound Care. 2013;2:588-92.

67. International Classification of Diseases, Ninth Revision, Clinical Modification (ICD-9-CM). National Center for Health Statistics. https://www.cdc.gov/nchs/ icd/icd9cm.htm. Accessed 29 Aug 2017.

68. What is CPT? American Academy of Professional Coders. https://www.aapc. com/resources/medical-coding/cpt.aspx. Accessed 29 Aug 2017.

69. Current Procedural Terminology. American Medical Association. https://www. ama-assn.org/practice-management/cpt-current-procedural-terminology. Accessed 29 Aug 2017

70. U.S. Food \& Drug Administration, National Drug Code Directory (https:// www.fda.gov/drugs/informationondrugs/ucm142438.htm. Accessed 29 Aug 2017.

71. Hazlehurst BL, Kurtz SE, Masica A, Stevens VJ, McBurnie MA, Puro JE, Vijayadeva V, Au DH, Brannon ED, Sittig DF. CER Hub: An informatics platform for conducting comparative effectiveness research using multiinstitutional, heterogeneous, electronic clinical data. Int J Med Inform. 2015:84:763-73.

72. Hazlehurst B, McBurnie MA, Mularski RA, Puro JE, Chauvie SL. Automating quality measurement: a system for scalable, comprehensive, and routine care quality assessment. AMIA Annu Symp Proc. 2009;2009:229-33.

73. Williams RJ, Masica AL, McBurnie MA, Solberg LI, Bailey SR, Hazlehurst B, Kurtz SE, Williams AE, Puro JE, Stevens VJ. Documentation of the 5 as for smoking cessation by PCPs across distinct health systems. Am J Manag Care. 2014;20:e35-42.

74. Markides KS, Coreil J. The health of Hispanics in the southwestern United States: an epidemiologic paradox. Public Health Rep. 1986;101:253-65.

75. Balcazar AJ, Grineski SE, Collins TW. The Hispanic health paradox across generations: the relationship of child generational status and citizenship with health outcomes. Public Health. 2015;129:691-7.

76. Galanter JM, Gignoux CR, Oh SS, Torgerson D, Pino-Yanes M, Thakur N, Eng C, Hu D, Huntsman S, Farber HJ, Avila PC, Brigino-Buenaventura E, LeNoir MA, Meade K, Serebrisky D, Rodriguez-Cintron W, Kumar R, RodriguezSantana JR, Seibold MA, Borrell LN, Burchard EG, Zaitien N: Differential methylation between ethnic sub-groups reflects the effect of genetic ancestry and environmental exposures. Elife 2017;3(6). doi: https://doi.org/ 10.7554/eLife.20532.

77. Bick J, Naumova O, Hunter S, Barbot B, Lee M, Luthar SS, Raefski A, Grigorenko EL. Childhood adversity and DNA methylation of genes involved in the hypothalamus-pituitary-adrenal axis and immune system: whole-genome and candidate-gene associations. Dev Psychopathol. 2012;24:1417-25.

78. Arrieta MC, Stiemsma LT, Dimitriu PA, Thorson L, Russelll S, Yurist-Doutsch S, Kuzeljevic B, Gold MJ, Britton HM, Lefebvre DL, Subbarao P, Mandhane P, Becker A, McNagny KM, Sears MR, Kollman T. CHILD Study Investigators, Mohn WW, Turvey SE, Finlay BB: Early infancy microbial and metabolic alterations affect risk of childhood asthma. Sci Transl Med. 2015;7:3-7. ra152

79. Miller GE, Engen PA, Gillevet PM, Shaikh M, Sikaroodi M, Forsyth CB, Mutlu E, Keshavarzian A. Lower neighborhood socioeconomic status associated with reduced diversity of the colonic microbiota in healthy adults. PLOS ONE. 2016;11:e0148952.

80. Seeman TE, McEwen BS, Rowe JW, Singer BH. Allostatic load as a marker of cumulative biological risk: MacArthur studies of successful aging. Proc Natl Acad Sci U S A 2001 Apr 10;98(8):4770-4775. Epub 2001 Apr 3.

81. Felitti VJ, Anda RF, Nordenberg D, Williamson DF, Spitz AM, Edwards V, Koss MP, Marks JS. Relationship of childhood abuse and household dysfunction to many of the leading causes of death in adults. The Adverse Childhood Experiences (ACE) Study. Am J Prev Med. 1998;14:245-58.

82. Suglia SF, Duarte CS, Chambers E, Boynton-Jarrett R. Cumulative Social Risk and Childhood Obesity. Pediatrics. 2012;129(5):e1173-9.

83. Ma J, Rosas $L G, L v$ N. Precision lifestyle medicine: A new frontier in the science of behavior change and population health. Am J Prev Med. 2016;50:395-7.

84. EHR incentive program. Eligible professional Meaningful Use Core Measures, Measure 9 or 13. Stage 1 (2014 Definition). Last updated: May 2014: Recording smoking status. Centers for Medicare and Medicaid. https:/Www.cms.gov/ Regulations-and-Guidance/Legislation/EHRIncentivePrograms/downloads/9 Record_Smoking_Status.pdf. Accessed 31 Aug 2017.

85. HRSA Health Center Program: Uniform Data System: Reporting Instructions for 2016 Health Center Data. Table 3B Demographic Characteristics -Patients 
by Sexual Orientation and Gender Identity. 2016 UDS Manual - November 4, 2016 V1.1, OMB Number: 0915-0193, Expiration Date: 02/28/2018. https:// bphc.hrsa.gov/datareporting/reporting/2016udsreportingmanual.pdf. Accessed 31 Aug 2017.

86. Patient identification and matching: final report. Office of the National Coordinator for Health Information Technology, 2014. https:/www.healthit. gov/sites/default/files/patient_identification_matching_final_report.pdf. Accessed 31 Aug 2017.

87. HealthlT.gov. Building data infrastructure to support patient centered outcomes research (PCOR). Patient matching, aggregating and linking (PMAL). https://www.healthit.gov/policy-researchers-implementers/patientmatching-aggregating-and-linking-pmal. Accessed 31 Aug 2017.

88. Jones NA: Update on the U.S. Census Bureau's race and ethnic research for the 2020 Census. https://www.census.gov/content/dam/Census/newsroom/ press-kits/2014/article_race_ethnic_research_2020census_jones.pdf. Accessed 31 Aug 2017.

89. NIH Policy and Guidelines on The Inclusion of Women and Minorities as Subjects in Clinical Research Effective, March 1994; (https://grants.nih.gov/ grants/guide/notice-files/not94-100.html. Amended Oct 2001. https://grants. nih.gov/grants/funding/women_min/guidelines_amended_10_2001.htm. Accessed 31 Aug 2017.

90. Oh SS, Galanter J, Thakur N, Pino-Yanes M, Barcelo NE, White MJ, De Bruin DM, Greenblatt RM, Bibbins-Domingo K, Wu AH, Borrell LN, Gunter C, Powe NR, Burchard EG. Diversity in Clinical and Biomedical Research: A Promise Yet to Be Fulfilled. PLoS Med. 2015;12:e1001918.

91. Yang J, Xu WW, Hu SJ. Heart failure: advanced development in genetics and epigenetics. Biomed Res Int. 2015;2015:352734.

92. Greco CM, Condorelli G. Epigenetic modifications and noncoding RNAs in cardiac hypertrophy and failure. Nat Rev Cardiol. 2015;12:488-97.

93. Iordanidou M, Loukides S, Paraskakis E. Asthma phenotypes in children and stratified pharmacological treatment regimens. Expert Rev Clin Pharmacol. 2017;10:293-303.

94. Popejoy AB, Fullerton SM. Genomics is failing on diversity (comment). Nature. 2016;538:161-4.

95. Trans-Omics for Precision Medicine (TOPMed) Program. https://www.nhlbi. nih.gov/research/resources/nhlbi-precision-medicine-initiative/topmed. Accessed 29 Aug 2017.

96. Dominguez K, Penman-Aguilar A, Chang M, Moonesinghe R, Castellanos T, Rodriguez-Lainz A, Schieber R. Vital signs: leading causes of death, prevalence of diseases and risk factors, and use of health services among Hispanics in the United States - 2009-2013. Morb Mortal Wkly Rep. 2015;64:469-78.

97. Zsembik BA, Fennell D. Ethnic variation in health and the determinants of health among Latinos. Soc Sci Med. 2005;61:53-63.

98. Ennis SR, Ríos-Vargas M, Albert N: 2010 Census briefs: the Hispanic population: 2010. May 2011, U.S. Department of Commerce, economics and statistics administration. CR2010BR-04.

99. Behavioral Risk Factor Surveillance System (BRFSS). https://www.cdc.gov/ brfss/. Accessed 29 Aug 2017.

100. National Health Nutrition and Examination Survey (NHANES). https://www. cdc.gov/nchs/nhanes/. Accessed 29 Aug 2017.

101. Multi-Ethnic Study of Atherosclerosis (MESA). https:/www.mesa-nhlbi.org/. Accessed 29 Aug 2017

102. Crane HM, Lober W, Webster E, Harrington RD, Crane PK, Davis TE, Kitahata MM. Routine collection of patient-reported outcomes in an HIV clinic setting: the first 100 patients. Curr HIV Res. 2007;5:109-18.

103. Gold R, Nelson C, Cowburn S, Bunce A, Hollombe C, Davis J, Muench J, Hill C, Mital M, Puro J, Perrin N, Nichols G, Turner A, Mercer M, Jaworski V, Howard C, Abiles E, Shah A, Dudl J, Chan W, DeVoe J. Feasibility and impact of implementing a private care system's diabetes quality improvement intervention in the safety net: a cluster-randomized trial. Implement Sci. 2015;10:83. https://doi.org/10.1186/s13012-015-0259-4.

104. Johnson K, Grossmann C, Anau J, Greene S, Kimbel K, Larson E, Newton K. Integrating research into health care systems: executive's views. Perspectives, Discussion Paper: Institute of Medicine; 2015. https:/nam.edu/perspectives2015-integrating-research-into-health-care-systems-executives-views/. Accessed 31 Aug 2017.

105. Proctor BD, Semega JL, Kollar MA. U.S. Census Bureau, Current Population Reports, P60-256(RV), Income and Poverty in the United States: 2015, U.S. Government Printing Office, Washington, DC, 2016.

106. Sung NS, Crowley WF, Genel M, Salber P, Sandy L, Sherwood LM, Johnson SB, Catanese V, Tilson H, Getz K, Larson EL, Scheinberg D, Reece EA, Slavkin
H, Dobs A, Grebb J, Martinez RA, Korn A, Rimoin D. Central challenges facing the national clinical research enterprise. JAMA. 2003;289:1278-87.

107. Cohen JJ, Gabriel BA, Terrel C. The case for diversity in the healthcare workforce. Health Aff. 2002;21:90-102.

108. Smedley BD, Stith Butler A, Bristow LR, editors. In the Nation's Compelling Interest: Ensuring Diversity in the Health-Care Workforce. Institute of Medicine (US) Committee on Institutional and Policy-Level Strategies for Increasing Diversity of the U.S. Healthcare Workforce. National Academies Press, Washington, DC, 2004.

\section{Submit your next manuscript to BioMed Central and we will help you at every step:}

- We accept pre-submission inquiries

- Our selector tool helps you to find the most relevant journal

- We provide round the clock customer support

- Convenient online submission

- Thorough peer review

- Inclusion in PubMed and all major indexing services

- Maximum visibility for your research

Submit your manuscript at www.biomedcentral.com/submit
Biomed Central 